Document downloaded from:

http://hdl.handle.net/10251/60269

This paper must be cited as:

Casano, L.; Del Campo, E.; García Breijo, FJ.; Reig Armiñana, J.; Gasulla, F.; Del Hoyo, A.; Guéra, A.... (2011). Two Trebouxia algae with different physiological performances are everpresent in lichen thalli of Ramalina farinacea. Coexistence versus Competition. Environmental Microbiology. 13(3):806-818. doi:10.1111/j.1462-2920.2010.02386.x.

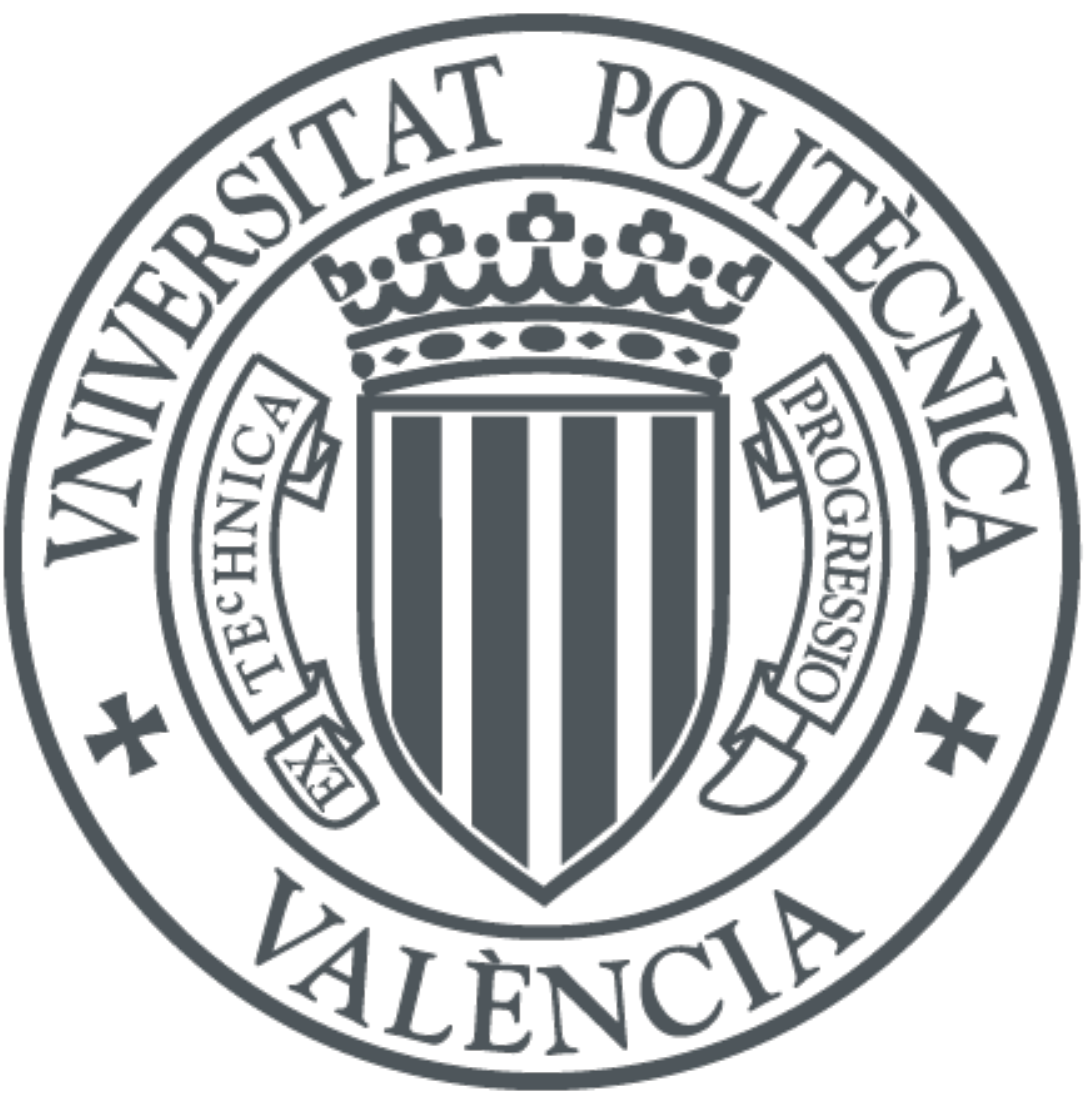

The final publication is available at

http://dx.doi.org/10.1111/j.1462-2920.2010.02386.x

Copyright WILEY-BLACKWELL

Additional Information 


\section{Two Trebouxia algae with different physiological performances are ever-present in lichen thalli of Ramalina farinacea. Coexistence versus Competition?}

Leonardo M. Casano, ${ }^{1}$ Eva M. del Campo, ${ }^{1 *}$ Francisco J. García-Breijo, ${ }^{2,3}$ José Reig-Armiñana, ${ }^{2}$ Francisco Gasulla, ${ }^{2}$ Alicia del Hoyo, ${ }^{1}$ Alfredo Guéra ${ }^{1,2}$ and Eva Barreno ${ }^{2}$ ${ }^{1}$ Department of Plant Biology, University of Alcalá, 28871-Alcalá de Henares, Madrid, Spain.

${ }^{2}$ Universitat de València, Botánica, ICBIBE -Jardí Botánic, Fac. C. Biológicas, C/ Dr Moliner 50. 46100-Burjassot. Valencia; Spain. ${ }^{3}$ Dpto. Ecosistemas Agroforestales, Universidad Politécnica de Valencia, Camino de Vera $s / n$, 46022-Valencia, Spain.

\section{Summary}

Ramalina farinacea is an epiphytic fruticose lichen that is relatively abundant in areas with Mediterranean, subtropical or temperate climates. Little is known about photobiont diversity in different lichen populations. The present study examines the phycobiont composition of several geographically distant populations of $\boldsymbol{R}$. farinacea from the Iberian Peninsula, Canary Islands and California as well as the physiological performance of isolated phycobionts. Based on anatomical observations and molecular analyses, the coexistence of two different taxa of Trebouxia (working names, TR1 and TR9) was determined within each thallus of $\boldsymbol{R}$. farinacea in all of the analysed populations. Examination of the effects of temperature and light on growth and photosynthesis indicated a superior performance of TR9 under relatively high temperatures and irradiances while TR1 thrived at moderate temperature and irradiance. Ramalina farinacea thalli apparently represent a specific and selective form of symbiotic association involving the same two Trebouxia phycobionts. Strict preservation of this pattern of algal coexistence is likely favoured by the different and probably complementary ecophysiological responses of each phycobiont, thus facilitating the proliferation of this lichen in a wide range of habitats and geographic areas.

\section{Introduction}

Lichen thalli represent a relatively well-balanced symbiotic system that can be regarded as a self-contained miniature ecosystem (Honegger, 1991). Lichen symbiogenesis involves the close morphological and physiological integration of a fungus (mycobiont) and at least a population of green algae and/or cyanobacteria (photobionts), resulting in a unique entity or holobiont (Barreno, 2004). More recently, it was proposed that lichens are more complex symbiotic systems than thought previously including non-photosynthetic bacterial communities as multifunctional partners in the holobiont (Barreno et al., 2008; Grube et al., 2009). Lichen symbioses are cyclical processes comparable to other symbioses such as corals, mycorrhiza, etc. Lichenization is a successful symbiosis as evidenced by the fact that lichens are found in almost all terrestrial habitats and geographic areas. The green algae in the genera Trebouxia and Asterochloris occur in at least $35 \%$ of all lichens but are rarely found in a freeliving state (Skaloud and Peksa, 2010). Gene sequence comparisons of the nuclear-encoded small subunit RNA (18S rRNA gene) and ultrastructural findings support the inclusion of Trebouxia in a distinct Trebouxiophyceae clade within Chlorophyta (Skaloud and Peksa, 2010). In addition, the diversity of Trebouxia and Asterochloris phycobionts has been extensively investigated on the basis of internal transcribed spacers (ITS) and actin sequence polymorphisms (DePriest, 2004; Doering and PierceyNormore, 2009; Skaloud and Peksa, 2010). More recently, the use of plastid 23S rRNA gene has been proposed as a complementary tool for the identification and phylogenetic analysis of lichen algae (Del Campo et al., 2010).

Patterns of fungal-algal association can be described in terms of selectivity and specificity (Yahr et al., 2004). Selectivity is defined by the association frequency of compatible partners, and specificity by the taxonomic range of acceptable partners, which could be influenced by the environment (Rambold et al., 1998; DePriest, 2004). 
Based on Combes' filter model (Euzet and Combes, 1980), Yahr and colleagues (2006) proposed a pattern for mycobiont-photobiont interactions and the mechanisms that structure them. The latter may differ considerably depending on the lichen species. Several mycobionts associate with a single species, or even a single clade of photobiont (Beck et al., 1998; Kroken and Taylor, 2000; Romeike et al., 2002; Piercey-Normore, 2006). However, the same photobiont may associate with several different lichen fungi (O'Brien et al., 2005). In addition, most of the studies on population structure have reported the presence of a single primary photobiont per thallus (e.g. Yahr et al., 2004; Muggia et al., 2008; Nelsen and Gargas, 2008). In other cases, multiple algal genotypes have been found in a single thallus (e.g. Guzow-Krzeminska, 2006; Ohmura et al., 2006), which may confer advantages in the lichen's ability to respond to environmental changes or to occupy diverse microenvironments (Piercey-Normore, 2006). Further support for this argument is obtained by considering lichen thalli as microecosystems in which the fungus is the host and the photobiont(s) the primary producer(s). In nature, there are multiple examples demonstrating that positive interactions among potential competitors can sustain the stable coexistence of multiple species (Gross, 2008; Haruta et al., 2009; Loarie et al., 2009).

Here we present the results of an in-depth morphological, molecular, and physiological study of the phycobiont composition of the fruticose lichen Ramalina farinacea and its diversity. The growth pattern of fruticose species constitutes an important advantage in the separation of individuals prior to DNA extraction because growing thalli emerge from a single punctual holdfast. Microscopic observations and molecular markers were used to investigate the diversity of phycobiont composition in lichen thalli obtained from geographically distant localities, as Iberian Peninsula, Canary Islands and California, characterized by diverse environmental conditions within the context of Mediterranean and temperate climates. These studies were carried out on phycobionts within the thallus as well as those isolated in axenic culture. Using chlorophyll (Chl) a fluorescence analyses, we identified several important photosynthetic traits in axenic cultures of phycobionts. Overall, the results provided evidence that there are two different taxa belonging to the genus Trebouxia. They differ in their morphologies as well as in physiology, and successfully coexist within the same lichen thallus.

\section{Results}

Morphological analysis of phycobionts from

Ramalina farinacea

In this study, LM and TEM were used to characterize the structure and ultrastructure of $R$. farinacea photobionts. Thalli from all the studied populations of $R$. farinacea always contained two types of Trebouxia phycobionts (working names: TR1 and TR9). These photobionts are structurally well characterized. The main morphological features of these algae, as observed in the thalli and in cell culture, are compared in Table 1 and Figs 1 and 2. TR1 and TR9 phycobionts were usually grouped by morphotype and located near the chondroid tissue, in close contact with the hyphae solely in the photobiont layer (Fig. 1A, B and F). Additionally, TEM demonstrated the joint occurrence of the two algae (Fig. 1B) although groups of a single photobiont type are more frequent.

Table 1. Main morphological features of the algae TR1 and TR9.

\begin{tabular}{|c|c|c|c|}
\hline Morphological attributes & & TR1 & TR9 \\
\hline \multirow[t]{2}{*}{ Cell size } & Cell diameter $(\mu \mathrm{m})$ & $9.76 \pm 0.12^{*}$ & $15.26 \pm 0.10^{*}$ \\
\hline & Cell diameter ( $\mu \mathrm{m})$ (in culture) & $6.37 \pm 0.11^{*}$ & $10.01 \pm 0.10^{*}$ \\
\hline \multirow[t]{5}{*}{ Cell wall } & Thickness (nm) & $304.50 \pm 6.10^{*}$ & $594.16 \pm 5.37^{*}$ \\
\hline & Thickness (nm) (in culture) & $147.36 \pm 3.58^{*}$ & $412.67 \pm 6.49^{*}$ \\
\hline & & L1. 50 & L1. 70-90 \\
\hline & Thickness of cell wall & L2. 75-90 & L.2. $90-110$ \\
\hline & & L4. 160-200 & \\
\hline \multirow[t]{3}{*}{ Pyrenoid } & Pyrenoid matrix & + & - \\
\hline & Pyrenoglobules & + & - \\
\hline & Thylakoids invaginations & + & - \\
\hline \multirow[t]{2}{*}{ Chloroplast } & Shape & Lobated & Lobated \\
\hline & Stacked thylacoids & $\leq 3$ & Numerous \\
\hline \multirow[t]{2}{*}{ Large electron dense vesicles } & Number & Few $(\leq 4)$ & Numerous $(>5)$ \\
\hline & Size $(\mu \mathrm{m})$ & $<0.6$ & $\geq 0.6-1.5 \mu \mathrm{m}$ \\
\hline Zoospores (in culture) & & + & + \\
\hline
\end{tabular}

Unless otherwise stated, measurements were performed in thallus, from a random selection of $R$. farinacea specimens from Sierra El Toro, Castellón, Spain $(n=15)$. The data are the means of 150 measurements \pm the standard error of the means (SEM). All measurements were performed by TEM, except those corresponding to cell diameter, which were by LM. Values with asterisks are significantly different at $P<0.01$ (comparisons made with independent Student's t-test). +: presence; -: absence. 

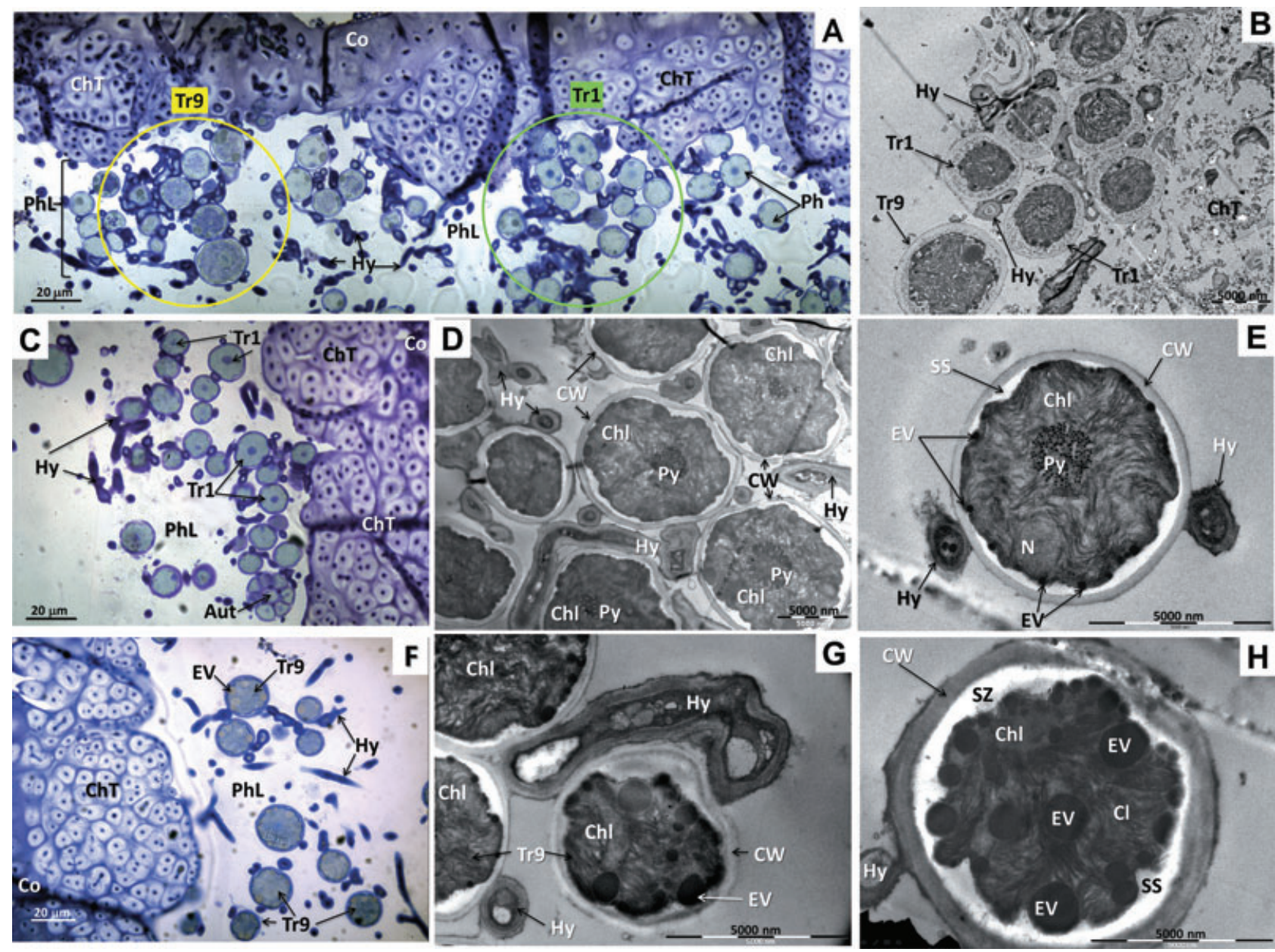

Fig. 1. A, C and F. Location by LM of the two Trebouxia algae, TR1 and TR9, in transverse sections of a Ramalina farinacea thallus stained with toluidine blue.

$\mathrm{B}, \mathrm{D}, \mathrm{E}, \mathrm{G}$ and $\mathrm{H}$. Anatomy of TR1 and TR9 by TEM of ultrathin sections of a $R$. farinacea thallus.

B. Location of TR1 and TR9 in the photobiont layer.

C-E. TR1 phycobiont, filled with a chloroplast containing a large central pyrenoid

F-H. TR9 phycobiont, with a lobated chloroplast filling the protoplast and containing numerous large electron-dense vesicles.

Abbreviations: Aut, autospores; Chl, chloroplast; ChT, chondroid Tissue; Co, cortex; CT, cytoplasmic tufts; CW, cell wall; EV, electron-dense vesicles; Hy, hyphae; N, nucleus; PhL, photobiont layer; Py, pyrenoid; SS, secretion space.

Fig. 2. Ultrastructure of TR1 and TR9 phycobionts in culture by TEM micrographs of ultrathin sections.

A, B, C. TR1 phycobionts.

A. Cell with a central massive single lobated chloroplast and a central pyrenoid.

B. The chloroplast is loosely packed with thylakoidal membranes closely associated in stacks of three at the most. The outer lamellae of the thylakoid stack develop tubules penetrating the pyrenoid matrix as finger-like invaginations. Osmiophilic pyrenoglobules are associated with these tubules. Pyrenoid morphology corresponds to the impressa-type.

C. Cell wall and secretion space. The cell wall shows four layers. The outermost (1) is thin and electron-opaque; followed by an electron-transparent layer (2), an electron-opaque layer (3), and finally, towards the interior (4), a heavier layer made up from the materials contained in the secretion space. In this space, several secretion vesicles coming from the cytosol can be observed.

D, E, F. TR9 phycobionts.

D. Cell with a large lobated chloroplast containing numerous electron-dense vesicles.

E. Chloroplast in the peripheral zone. The outer thylakoids are grouped in stacks made up by numerous membranes, as in the grana of vascular plants. Several starch granules, a mitochondrion, and electron-dense vesicles are well stand out.

F. Cell wall and secretion space. The cell wall shows three layers. The outermost (1) is thin and dense while the intermediate layer (2) is clearer. The dense internal layer (3) is formed from the materials contained in the secretion space.

Abbreviations: Chl, chloroplast; ChM, chloroplast membrane; CM, cellular membrane; CW, cell wall; Cy, cytosol; EV, electron-dense vesicles; $\mathrm{Gr}$, grana; Mit, mitochondria; N, nucleus; Nu, nucleolus; Pg, pyrenoglobules; Py, pyrenoid; S, starch; SS, secretion space; SV, secretion vesicles; T, tubules; TM, thylakoids membranes. 
Successful coexistence of two algae in R. farinacea lichens
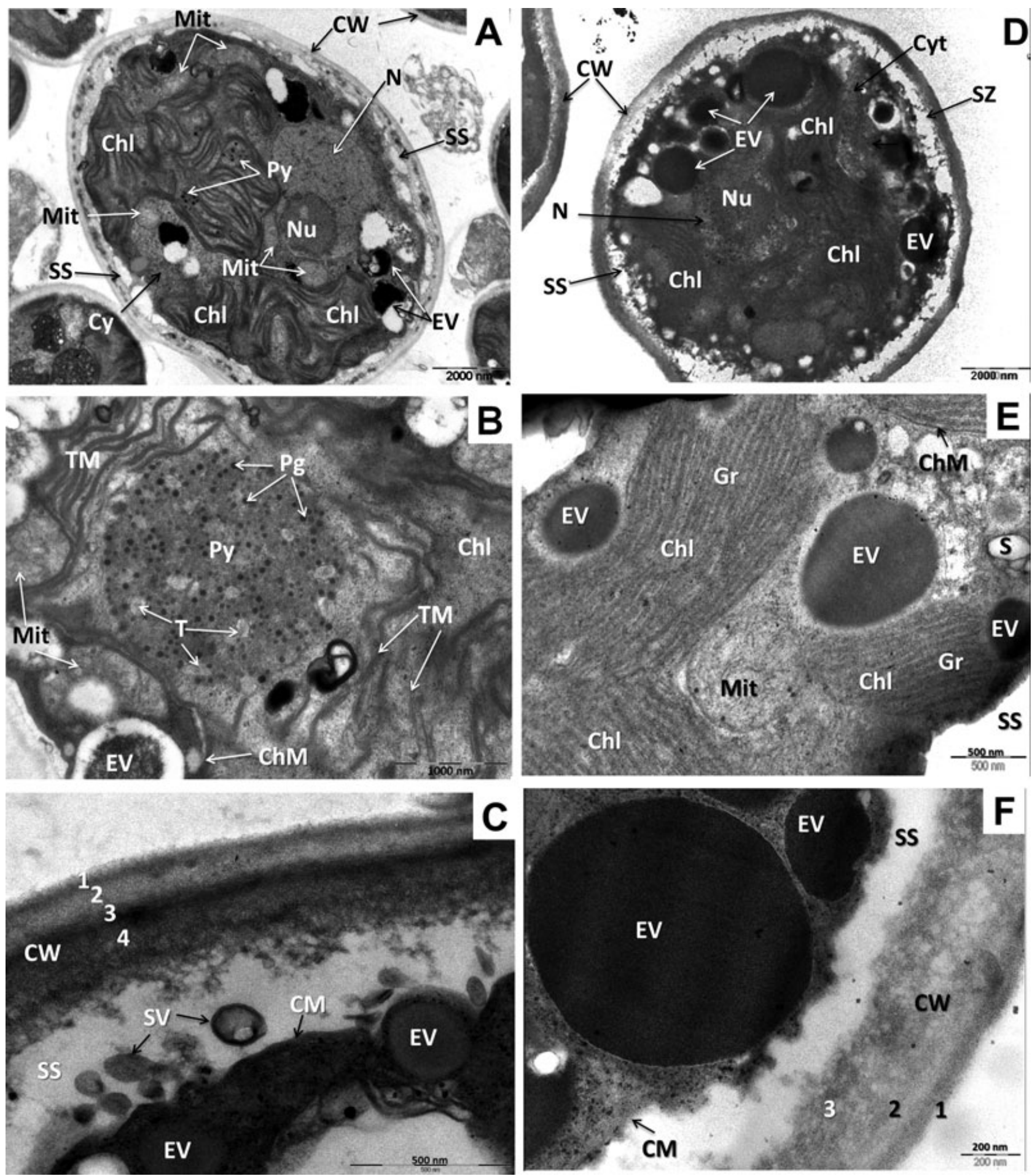

LM and TEM anatomy of TR1 and TR9 phycobionts

Photobiont identification was based on the following morphological features: (i) vegetative-cell size and cell-wall thickness; (ii) pyrenoid structure; (iii) electron-dense vesicles; and (iv) chloroplast shape and grana type. Two different taxa of the genus Trebouxia were found to be consistently present in $R$. farinacea thalli. As seen using LM, TR1 and TR9 phycobiont cells differ in size both in thallus and in culture, being smaller in the later environment (Table 1). On TEM, the cell walls of TR1 algae varied in thickness (Table 1), and were made up of four layers 


\section{M. Casano et al.}

(Fig. 2C). The cell walls of TR9 were thicker than in TR1 (Table 1) and consisted of only three well-differentiated layers (Fig. 2F, Table 1). These structures in culture conditions were maintained but exhibiting thinner walls, probably due to the slower growth rate and lower nutrient availability. Both phycobionts had a central massive single star-shaped and lobed chloroplast. In TR1 cells, the lobes extending to the cellular margins were loosely packed. Thylakoids were often closely associated in stacks of three at the most (Figs 1E, 2A and B). A large central part of the chloroplast was occupied by the pyrenoid (Figs 1D and $E, 2 A$ and $B$ ); the outer lamellae of the thylakoid stacks included tubules that penetrated the pyrenoid matrix and were either long or short depending on the section (Fig. 2B); osmiophilic pyrenoglobules were associated with these finger-like straight and not branched invaginations, consistent with the impressatype described by Friedl (1989). In TR9 cells, the chloroplast occupied most of the cell volume; the most peripheral thylakoids were grouped in stacks shaped by numerous membranes, similar to the grana in vascular plants (Figs $1 \mathrm{H}$ and 2E). Large spherical vesicles $(\geq 0.6-1.5 \mu \mathrm{m})$ with an electron-dense content made up of lipids were seen throughout the cytoplasm and were especially abundant at the periphery and near the mitochondria (Fig. 2D). These vesicles were observed within the lichen thallus (Fig. $1 \mathrm{G}$ and $\mathrm{H}$ ) and in culture (Fig. 2D-F). The pyrenoid matrix was usually absent or could not be clearly differentiated and pyrenoglobules were not observed. Only two Asterochloris species are known to share this feature (Friedl, 1989). Zoospores with distinct flagella have been recorded in both TR1 and TR9, but only in cultures (Table 1).

Molecular analyses of phycobionts from R. farinacea confirm the coexistence of two different Trebouxia taxa

In previous work, we sequenced a portion of the chloroplast-encoded 23S rRNA gene in several Trebouxia and Asterochloris algae, including a Trebouxia phycobiont isolated from a population of Ramalina farinacea collected in Sierra del Toro (Castellón, Spain) (Del Campo et al., 2010). The obtained sequence spanned position 759-2596 in the homologous Escherichia coli 23S rRNA gene and revealed the presence of distinct and species-specific group I introns within the gene (Del Campo et al., 2009; 2010). This first characterized Trebouxia photobiont corresponded to the present TR9 phycobionts. TR9 algae were initially named Trebouxia sp. (accession EU600236, Del Campo et al., 2010). In this work, we sequenced the same portion of the 23S rRNA gene of the isolated TR1 phycobionts of $R$. farinacea, which was shown to be highly homologous to that of Trebouxia jamesii UTEX 2233 (accession EU352794,
Del Campo et al., 2010). The number, sequence, and distribution of introns within the same portion of 23S rRNA gene differed greatly between TR1 and TR9.

In the present study, the photobiont composition of 36 thalli of $R$. farinacea collected from different Mediterranean and temperate regions was analysed (Table S1). In accordance to the above-mentioned information and in order to determine the presence of TR1 and/or TR9 phycobionts in these thalli, two distinct group I introns were amplified, each present in one phycobiont but absent in the other (see Experimental procodures). Figure 3B and $C$ shows the products of a representative amplification experiment performed with the DNA extracted from individual thalli and either the CL2263F/CL2263R or the cL781F/CL781R primer pair. Significantly, both primer pairs amplified all assayed samples. Sequencing of the amplified products confirmed the presence of TR1 and TR9 phycobionts in all studied lichen thalli independent of its native geographical localization.

In addition, we designed two different primer pairs, ITSTR1f/ITS-TR1r and ITS-TR9f/ITS-TR9r, homologous to the nrITS sequences of the isolated phycobionts TR1 and TR9 respectively. PCRs were carried out with DNA obtained from each lichen thallus (Rf) and the phycobionts TR1 and TR9 isolated in culture. Figure 3D depicts a gel electrophoresis of the reaction products, showing that the primer pair ITS-TR1f/ITS-TR1r amplified DNA from both the lichen thallus and the TR1 phycobiont but not from the TR9 phycobiont. By contrast, the primer pair ITS-TR9f/ITS-TR9r amplified DNA from both the lichen thallus and the TR9 phycobionts but not from the TR1 phycobionts. These findings support our initial hypothesis of the presence of two different coexisting Trebouxia species, corresponding to TR1 and TR9, within the same lichen thallus.

\section{Growth and photosynthetic behaviour of Ramalina farinacea photobionts}

Morphological and molecular results suggest a highly specific and selective pattern of association of the lichen-forming fungus $R$. farinacea, since the same two phycobionts, TR1 and TR9, were found in all lichen thalli studied. To search for physiological differences between the two $R$. farinacea phycobionts, the effects of temperature and light on the growth and photosynthetic traits of isolated and cultured TR1 and TR9 algae were studied. It should, however, be noted that while the physiological performance of algae in culture was assumed to be representative of that in symbiosis, further experiments with entire thalli (e.g. transplantation of thalli to higher or lower irradiances) are needed to confirm this assump- 


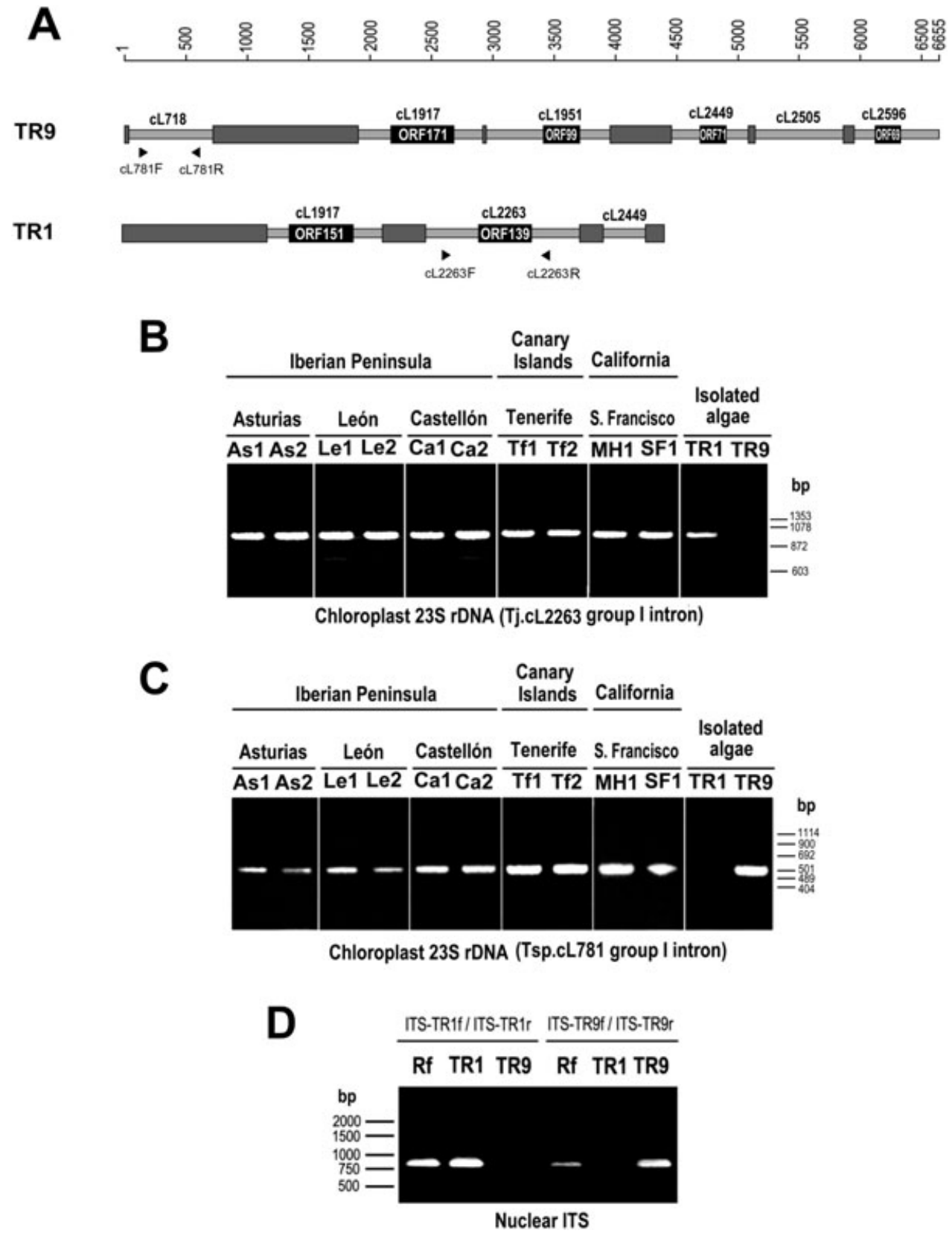

Fig. 3. A. Genetic maps of the sequenced portion of plastid LSU rDNA in TR1 and TR9 phycobionts (position 755-2535 in E. coli). The dark-grey boxes represent exons. Introns are depicted as light-grey boxes between exons. Intron names (according to Johansen and Haugen, 2001) are indicated above each intron. Open reading frames (ORFs) encoding putative homing endonucleases are depicted as black boxes within introns. Primer positions are indicated below each map with arrows.

B. Agarose gel electrophoresis of PCR amplification products (1.5\% agarose) obtained with the CL781F/CL781R primer pair and DNA extracted either from lichen thalli collected at different geographic locations (As, Asturias; Le, León; Ca, Castellón, Tf, Tenerife, MH, Monte Hamilton; SF, San Francisco) or from isolated and axenically propagated TR1 and TR9 phycobionts. Molecular size markers are indicated on the right. C. PCR amplification products obtained with the cL2263F/cL2263R primer pair and DNA extracted either from lichen thalli collected in different geographic locations or from isolated TR1 and TR9 phycobionts. Molecular size markers are indicated on the right.

D. PCR amplification products obtained with the ITS-TR1f/ITS-TR1r and ITS-TR9f/ITS-TR9r primer pairs and DNA extracted either from a lichen thallus (Rf) collected at Sierra El Toro (Castellón, Spain) or from isolated TR1 and TR9 phycobionts. Molecular size markers are indicated on the left. 


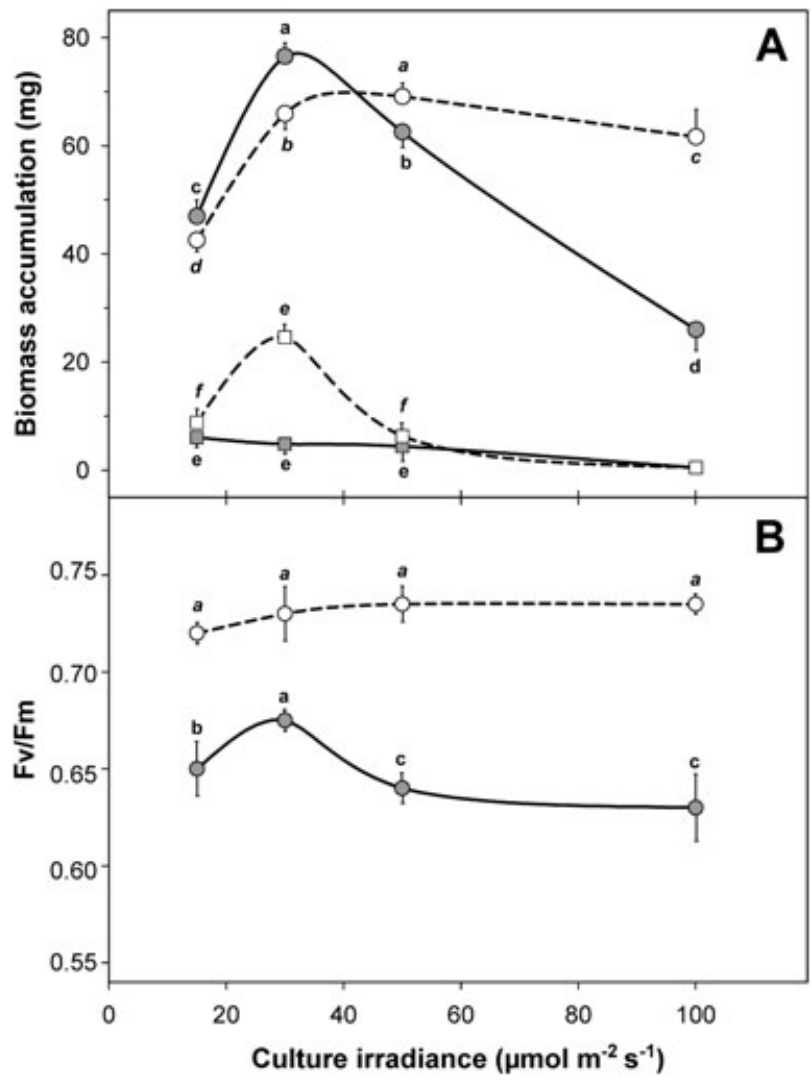

Fig. 4. Effects of temperature and irradiance during culture on growth and photosynthesis in isolated TR1 and TR9 phycobionts. A. TR9 and TR1 biomass accumulation after 30 days of culture at $17^{\circ} \mathrm{C}$ or $20^{\circ} \mathrm{C}$ and the indicated irradiances. Grey and white circles represent TR1 and TR9 phycobionts cultured at $17^{\circ} \mathrm{C}$ respectively. Grey and white squares represent TR1 and TR9 phycobionts cultured at $20^{\circ} \mathrm{C}$ respectively. Data are the mean values of five independent replicates (+ or $-\mathrm{SD}$ ).

B. Maximum quantum yield of PSII $\left(F_{\mathrm{v}} / F_{\mathrm{m}}\right)$ of TR1 and TR9 phycobionts cultured at $17^{\circ} \mathrm{C}$ and four different light intensities during 30 days. Data are the mean values of five independent replicates ( \pm SD). Grey and white circles represent TR1 and TR9 phycobionts respectively. Different normal and italic letters indicate significant differences among culture conditions for TR1 and TR9 phycobionts respectively (LSD test).

tion. Figure 4A shows the fresh weight reached by TR1 and TR9 after 30 days at $17^{\circ} \mathrm{C}$ or $20^{\circ} \mathrm{C}$ and $15-$ $100 \mu \mathrm{mol} \mathrm{m} \mathrm{m}^{-2} \mathrm{~s}^{-1}$ of PAR. Both species grew better at the lower temperature; however, at $20^{\circ} \mathrm{C}$ the negative impact of the high temperature was less on TR9 than on TR1, whose growth was almost inhibited. This general trend was similarly influenced by light intensity. At $17^{\circ} \mathrm{C}$, the maximum biomass of TR1 and TR9 was obtained at an irradiance of 30 and $50 \mu \mathrm{mol} \mathrm{m} \mathrm{m}^{-2} \mathrm{~s}^{-1}$ respectively. While the highest irradiance (at $17^{\circ} \mathrm{C}$ ) negatively affected the growth of both species, the biomass accumulation of TR1 decreased by c. $56 \%$ with respect to the maximum value but only by c. $6 \%$ in the case of TR9.
The effects of light on photosynthesis were studied through modulated fluorescence analyses. Since the low algal biomass at $20^{\circ} \mathrm{C}$ significantly increased the experimental error of fluorescence measurements, rendering non-reliable data, the experiments were carried out only in cultures growing at $17^{\circ} \mathrm{C}$. The fluorescence parameter $F_{\mathrm{v}} / F_{\mathrm{m}}$, provides an estimate of the maximum quantum efficiency of PSII photochemistry, showing normal values of about 0.8 for healthy leaves of vascular plants, independently of tissue structure, cell number or total Chl content (Björkman and Demmig, 1987; Baker and Oxborough, 2004). Registered values of $F_{\mathrm{v}} / F_{\mathrm{m}}$ for lichen thalli are lower, usually above 0.7 , but there are also normal values as low as 0.67 for unstressed lichens with green phycobionts (Demmig-Adams et al., 1990). Decrease of $F_{\mathrm{v}} / F_{\mathrm{m}}$ could result from a decrease in the fraction of PSII centres that are capable of photochemistry and/or an increase of non-photochemical quenching (NPQ) (Baker and Oxborough, 2004). $F_{\mathrm{v}} / F_{\mathrm{m}}$ was greater in TR9 than in TR1 at all culture irradiances (Fig. 4B). The $F_{\mathrm{v}} / F_{\mathrm{m}}$ values in TR9 remained nearly constant. In contrast, TR1 was more sensitive to changes in culture irradiance, as a maximum value of $F_{\mathrm{v}} / F_{\mathrm{m}}(0.678)$ recorded at $30 \mu \mathrm{mol} \mathrm{m} \mathrm{m}^{-2} \mathrm{~s}^{-1}$ decreased to 0.642 at $100 \mu \mathrm{mol} \mathrm{m}{ }^{-2} \mathrm{~s}^{-1}$, indicating the appearance of a slight photoinhibition when TR1 was cultured out of a narrow light intensity range. As shown in Figure 5, there was a clear difference in the photosynthetic light response of TR1 and TR 9 cultured at different light intensities. TR1 showed similar values of the relative quantum yield of electron transfer at PSII ( $\Phi_{P S I I}$, a measure of the overall efficiency of PSII reaction centres in the light, Fig. 5A) and relative electron transport rate (ETR, Fig. 5B), independent of the light during culture. However, TR9 exhibited increasing $\Phi_{\text {PSII }}$ and ETR values with increasing culture light intensity. Electron transport flow was saturated at approximately the same irradiance (c. $700 \mu \mathrm{mol} \mathrm{m}{ }^{-2} \mathrm{~s}^{-1}$ ) in both species and under all culture conditions. However, photosynthetic activity was higher in TR9 than in TR1.

Non-photochemical quenching, NPQ, is an estimation of the non-radiative dissipation of excitation energy and can thus be considered as photo-protective (Demmig-Adams and Adams III, 1996). Figure 5C shows the photosynthetic light response of NPQ in TR1 and TR9 cultured at different light intensities. The photosynthetic photon flux density (PPDF) response curves showed a correlation between NPQ and the culture light condition. The NPQ values increased with increasing light intensity up to $50 \mu \mathrm{mol} \mathrm{m} \mathrm{m}^{-2} \mathrm{~s}^{-1}$, without further changes in either TR1 or TR9. Interestingly, the highest NPQ values were observed in strains of TR9 cultured at higher light intensities. In addition, we examined the parameter $1-q_{p}$ (Fig. 5D), which is a measure of the reduction state of the first electron acceptor of PSII $\left(Q_{A}\right)$; high $1-q_{P}$ 


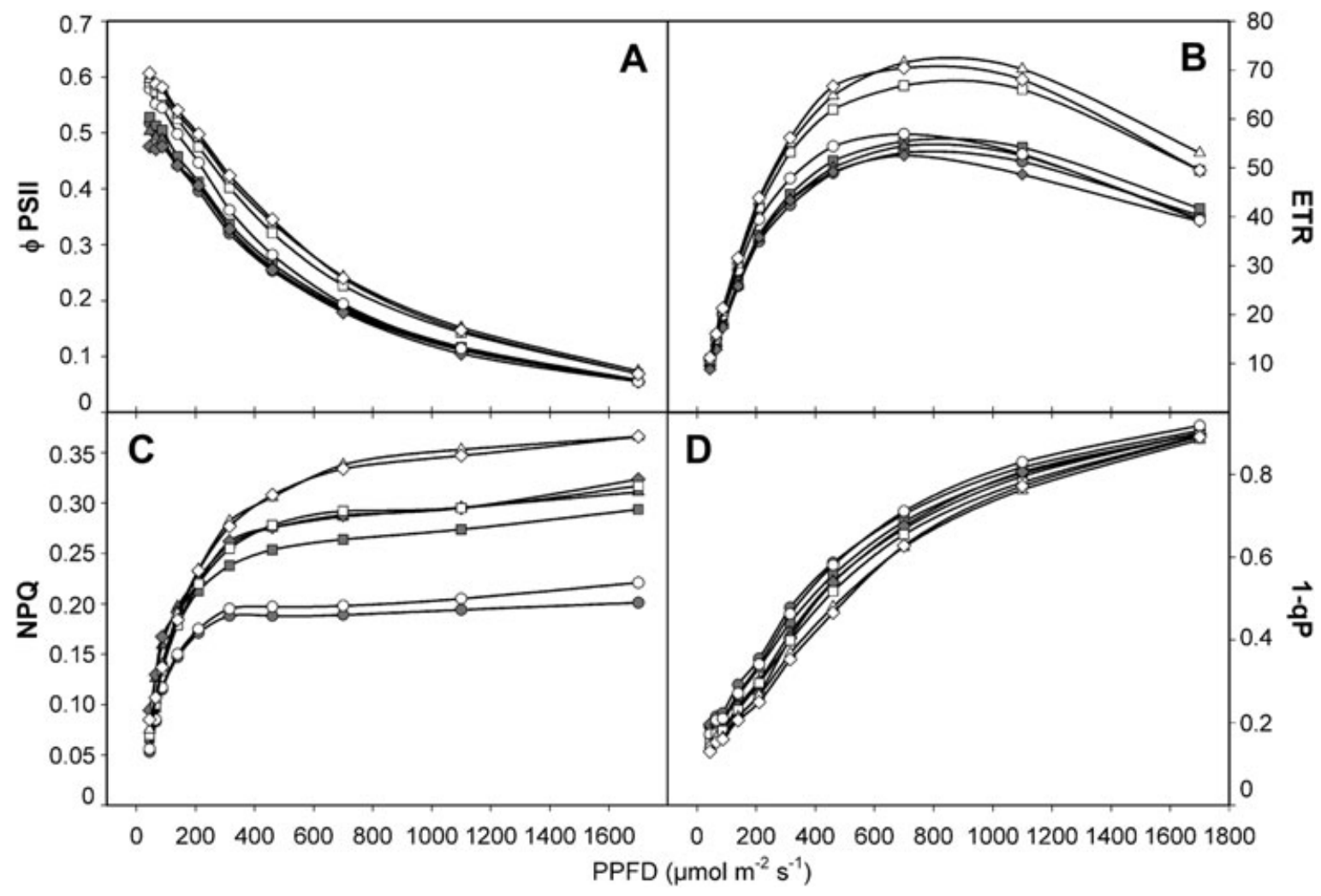

Fig. 5. Effects of irradiance during culture on fluorescence parameters in isolated TR1 and TR9 phycobionts. PPFD response curves of the actual quantum yield of the PSII (A, $\Phi_{\text {PSII }}$ ), relative electron transport rate $(B, E T R)$, non-photochemical quenching $(C, N P Q)$, and reduction state of the $Q_{A}\left(D, 1-q_{P}\right)$ for TR1 (grey) and TR9 (white) algae cultured at $17^{\circ} \mathrm{C}$ and at $15 \mu \mathrm{mol} \mathrm{m}^{-2} \mathrm{~s}^{-1}$ (circles), $30 \mu \mathrm{mol} \mathrm{m}^{-2} \mathrm{~s}^{-1}$ (squares), $50 \mu \mathrm{mol} \mathrm{m} \mathrm{s}^{-1} \mathrm{~s}^{-1}$ (triangles) and $100 \mu \mathrm{mol} \mathrm{m} \mathrm{s}^{-1}$ (rhombus). Data are the mean values of five independent replicates, with standard deviations (not shown) ranging from $0.5 \%$ to $3.2 \%$ of the corresponding mean values.

values are considered indicative of light stress (Weis and Berry, 1987). In both algae, lower values of $1-q_{p}$ were observed at low and moderate PPDF. The lowest $1-q_{p}$ values occurred in TR9 cultured at higher light intensities.

\section{Discussion}

Two Trebouxia taxa are ever-present in lichen thalli of Ramalina farinacea

To date, most of the studies on the population structure and patterns of symbiotic association in lichens have reported the presence of a single species of phycobiont per thallus. These findings are in agreement with the Gause's Principle (Gause, 1934), which postulates that the presence of closely related species with similar resource requirements within the same ecological niche often results in competitive exclusion(s) and the prevalence of the competitor that can maintain itself with the lowest level of the limiting resource. In the case of lichens, the thalli can be considered as self-contained miniature ecosystems (Honegger, 1991), with the algal layer as the single primary producer. However, there is increasing evidence that in some lichens, including Evernia mesomorpha (Piercey-Normore, 2006) and Protoparmeliopsis muralis (Guzow-Krzeminska, 2006), more than one algal genotype is present within the same thallus. The present study has demonstrated the coexistence within each lichen thallus of the same two Trebouxia algae (TR1 and TR9) analysed from geographically distant populations of the lichen $R$. farinacea. This is the first report of this type of symbiotic association in a lichen species supported by morphological, molecular, and physiological evidences. Unlike previous reports, in our study the simultaneous presence of TR1 and TR9 phycobionts was not restricted to a few analysed specimens but was instead found to occur in all lichen thalli, independent of their native geographic location. Moreover, the two coexisting algae clearly belonged to two different Trebouxia taxa, as determined by differences in key morphological traits (Table 1 , Figs 1 and 2) and in a large portion of the plastid-encoded $23 \mathrm{~S}$ rRNA gene (Fig. 3A). It should be pointed out that the rate of evolution of the chloroplast genome is slower than that of the nuclear genome and that there is a single sequence for each gene (even in the case of genes 


\section{M. Casano et al.}

repeated in different locations). Therefore, the detection of two different sequences of the same plastid-encoded gene in the same thallus clearly indicates the presence of two different taxa. On the other hand, when we analysed the algal nrITS associated with each lichen thallus employing the primer pair ITS1T-5'/ITS4T-3' (Kroken and Taylor, 2000), only one ITS sequence was found in all cases (data not shown). However, the use of two different primer pairs homologous to the ITS sequences of the isolated photobionts TR1 and TR9 allowed us to corroborate the presence of these Trebouxia species coexisting within the same lichen thallus (Fig. 3D). Therefore, care must be taken when 'general' primers are employed and only a single algal nrlTS sequence is detected. It may be indicative of the predominant photobiont while others in minority are not adequately amplified.

\section{Environmental conditions and the physiological performance of each algal species may modulate coexistence within the thallus}

Studies on other better known symbiotic systems where the host is heterotrophic and constitutes the habitat for photoautotrophs, such as reef-building corals, initially considered a single algal endosymbiont species per host. However, it is now recognized that several large and genetically diverse algal groups often co-occur within a single host species or colony (Wegley et al., 2007). Little and colleagues (2004) demonstrated dynamic variations of coral-algal associations according to environmentally related changes in the host's physiological needs. More recently, Jones and colleagues (2008) described dramatic alterations in the algal symbiont community of some coral species in response to environmental stress. Such polymorphic symbioses suggest that the identity of the algal partner(s) is as significant as that of the host in determining the physiology of the holobiont. In the case of lichen symbiosis, there is increasing experimental evidence that the association between phycobionts and mycobionts increases tolerance to stress conditions (e.g. Kranner et al., 2005; Kosugi et al., 2009). In our study, the observed physiological responses (growth and photosynthesis, Fig. 4) to temperature and light conditions indicated that TR9 performs better under relatively high temperature and irradiances whereas TR1 thrives under more temperate and shady conditions. These conclusions are supported by studies of biomass accumulation and photosynthetic traits, including the photochemical efficiency of PSII, the reduction state of $Q_{A}$, and the NPQ (Fig. 5). Non-photochemical quenching is an important process under stress conditions, transforming excess light energy that cannot be used in photosynthesis into heat. In vascular plants, it is associated with the xanthophyll cycle (Niyogi et al., 2005). However, the role of this cycle in lichen photobionts is thought to be limited, as alternative mechanisms of light dissipation are employed (Kopecky et al., 2005; Gasulla et al., 2009). In addition, recent results from our lab (Catalá et al., 2010) support an important role for NO in the photo-protection of phycobionts in $R$. farinacea. The diversity of habitats and local climates characteristic of the geographic locations (Table S1) sampled in the present study, along with the variety of ecological contexts in which $R$. farinacea proliferates, reflects the ecophysiological plasticity of this symbiosis as a mechanism allowing the lichen to cope and thus to adapt to changing and often stressful environments. Moreover, a positive interaction between the two phycobionts cannot be ruled out. According to Gross (2008) and Angert and colleagues (2009), positive interactions among competitors may produce stable and species-rich communities. Therefore, we propose that the constant presence of both Trebouxia phycobionts in $R$. farinacea is favoured by the different and probably complementary physiological behaviour of each algal species, thus improving the ecological fitness of the holobiont.

Vegetative reproduction of Ramalina farinacea seems to maintain a specific and selective association among symbionts

In addition to environmental conditions, an important mechanism controlling symbiotic associations may be the symbiont's reproductive mode. Lichens can reproduce sexually and asexually. Specifically, mycobionts produce either sexual spores, requiring 'de novo' associations with photobionts in each generation, or vegetative propagules containing fungal tissues and photobiont cells (Zoller and Lutzoni, 2003; Yahr et al., 2004; 2006). Lichens that depend on the cyclical establishment of fungal-photobiont associations to colonize varied wide-ranging habitats might require a relatively higher flexibility in the specificity and ecological selection of their photobionts. This flexibility would facilitate successful relichenizations by allowing for alternative partnerships in each habitat (Romeike et al., 2002). Among the lichens that disperse through soredia or other vegetative propagules, mycobiont and photobionts are jointly propagated within the same reproductive structure (Nelsen and Gargas, 2008). This reproduction strategy should allow to a strict preservation of the relationship among symbionts, although maintenance of symbiotic associations seems to be an option rather than a strict consequence of joint symbiont dispersal in lichens (Wornik and Grube, 2009). Ramalina farinacea propagates through vegetative propagules (soredia), which is consistent with the overall pattern of coexistence of the same two algal Trebouxia species in all sampled thalli. Our future work will deal with the origin and maintenance 
of genetic variability within $R$. farinacea phycobionts (and the possible relationship with mycobiont genotypes). We will try to discriminate between alternative hypotheses whether TR1 and TR9 are packed in each soredium or are gathered from the environment.

In conclusion, $R$. farinacea represents a novel pattern of lichen symbiosis that is maintained through joint propagation of the mycobiont and the same two Trebouxia phycobiont taxa. The preservation of this pattern seems to be favoured by the distinct and probably complementary ecophysiological responses of each phycobiont, which in turn permits the lichen to proliferate in very different habitats. In addition, these lichen provide an interesting model system to be studied within the context of hologenome theory of evolution (Rosenberg et al., 2009), which emphasizes the cooperation and competition among symbionts and their hosts, and to monitor the responses of organisms to current and future environmental changes.

\section{Experimental procedures}

\section{Ramalina farinacea sampling, photobiont isolation and culture}

Specimens of Ramalina farinacea (L.) Ach. were collected from seven different locations in the Iberian Peninsula and Canary Islands and from two sites in California (USA), as detailed in Table S1. Samples were dried out in the shaded open air for 1 day and then stored at $-20^{\circ} \mathrm{C}$ until needed. For photobiont isolation, $R$. farinacea thalli were collected in the air-dried state on Quercus rotundifolia Lam. at Sierra EI Toro (Castellón, Spain). Samples were frozen at $-20^{\circ} \mathrm{C}$ until the isolation experiment, 3 months after collection. TR1 and TR9 phycobionts were isolated in our laboratories according to Gasulla and colleagues (2010). Isolated phycobionts were cultured in liquid or semisolid Bold $3 \mathrm{~N}$ medium (Bold and Parker, 1962) in a growth chamber at $15^{\circ} \mathrm{C}$, under a $14 \mathrm{~h} / 10 \mathrm{~h}$ light/dark cycle (light conditions: $25 \mu \mathrm{mol} \mathrm{m}^{-2} \mathrm{~s}^{-1}$ ).

\section{Morphological analysis of 'in thallus' lichen photobionts and isolated algae}

Pieces of rehydrated $R$. farinacea thalli [from Sierra El Toro (Castellón, Spain)] were used to examine by TEM the TR1 and TR9 algae inside thallus. They were fixed in $2 \%$ Karnovsky fixative for $2 \mathrm{~h}$ at $4^{\circ} \mathrm{C}$. The specimens were then washed three times with $0.01 \mathrm{M} \mathrm{PBS}, \mathrm{pH} 7.4$, for 15 min each and fixed with $2 \% \mathrm{OsO}_{4}$ in $0.01 \mathrm{M} \mathrm{PBS}, \mathrm{pH} 7.4$, for $2 \mathrm{~h}$ at $4^{\circ} \mathrm{C}$. Thereafter, specimens were washed in $0.01 \mathrm{M}$ PBS, $\mathrm{pH} 7.4$, for $15 \mathrm{~min}$ and then dehydrated at room temperature in a graded series of ethanol, starting at $50 \%$ and increasing to $70 \%, 95 \%$ and $100 \%$ for no less than $20-30$ min for each step. The fixed and dehydrated samples were embedded in Spurr's resin according to manufacturer's instructions (http://www.emsdiasum.com/microscopy/technical/ datasheet/14300.aspx). To analyse isolated algae, cultured colonies were suspended in liquid Bold $3 \mathrm{~N}$ medium then added to an equal volume of $2 \%$ glutaraldehyde in the same medium. After $1 \mathrm{~h}$ at $4^{\circ} \mathrm{C}$, the samples were washed in $0.01 \mathrm{M}$ PBS buffer, $\mathrm{pH} 7.4$, and post-fixed with $1 \% \mathrm{OsO}_{4}$ in $0.01 \mathrm{M}$ PBS, $\mathrm{pH} 7.4\left(2 \mathrm{~h}\right.$ at $\left.4^{\circ} \mathrm{C}\right)$, then gently centrifuged, washed again, dehydrated through an ethanol series, and embedded in Spurr's resin as previously described for in thallus observations.

For light microscopy (LM) analyses, 1-2 $\mu \mathrm{m}$ sections were cut from samples ( $R$. farinacea thalli or isolated algae) embedded in Spurr's resin using a diamond knife (DIATOME Histo $45^{\circ}$ ) and an ultramicrotome (Ultratome Nova LKB Bromma). The sections were stained with $1 \%$ toluidine blue and observed with an Olympus Provis AX 70 microscope equipped with an Olympus Camedia C-2000 Z camera. For transmission electron microscopy (TEM), $90 \mathrm{~nm}$ sections were cut with a diamond knife (DIATOME Ultra $45^{\circ}$ ) using an ultramicrotome (Ultratome Nova LKB Bromma), mounted on copper grids of 100 mesh, and post-stained with $2 \%(\mathrm{w} / \mathrm{v})$ aqueous uranyl acetate and $2 \%$ lead citrate. The prepared sections were observed with a JEOL JEM-1010 (80 kV) electron microscope, equipped with a MegaView III digital camera and 'AnalySIS' image acquisition software, at the SCSIE service of the University of Valencia.

\section{Nucleic acids extraction, purification and PCR amplification}

Total DNA was extracted from each lichen thallus and from isolated Trebouxia phycobionts following the procedure of Cenis (1992). Isolated DNA was PCR-amplified with specific primers under the cycling conditions described in Del Campo and colleagues (2010). Amplification products were subjected to agarose electrophoresis and then purified and sequenced according to Del Campo and colleagues (2010). All oligonucleotides used in the PCRs and in the subsequent sequencing of the chloroplast 23S rDNA were designed based on the nucleotide sequence of the chloroplast 23S rRNA gene from Trebouxia aggregata (DDBJ/EMBL/ GenBank Accession No. L43542; Pombert et al., 2006) and on partial sequences obtained in our laboratory. The primers used for amplifying and sequencing of nrITS from isolated TR1 and TR9 were obtained from Kroken and Taylor (2000). The primers ITS-TR1f and ITS-TR1r, ITS-TR9f and ITS-TR9r, specific for each isolated photobionts, were designed based on the obtained global sequences of nrlTS from isolated TR1 and TR9.

List of oligonucleotides:

\section{cL2263R: 5'-GTAATACTACATTGGTGCGGAC-3' cL2263F: 5'-AGCACATCACAGAGAAGCTG-3' cL781F: 5'-TCATAACGGTGAAACCTAAGGC-3' cL781R: 5'-CAGAACGCCAAACCATATACCG-3' ITS-TR1f: 5'-ACACACGTCAAGCAATCAACTC-3' ITS-TR1r: 5'-CTGACCGGCAACCCGAAG-3' ITS-TR9f: 5'-AACATACCTTAAGCAATTAATTC-3' ITS-TR9r: 5'-TGACCGGCTAGCATTCAG-3'}

The cL2263F/cL2263R primer pair (Fig. 3A) is included within the group IB4 intron Tja.cL2263 of the chloroplastencoded 23S rRNA gene (Del Campo et al., 2010). This intron is exclusive to TR1 phycobionts. The $\mathrm{CL} 781 \mathrm{~F} / \mathrm{CL} 781 \mathrm{R}$ 
primer pair (Fig. 3a) is included within the group IA3 intron Tsp.cL781 of the chloroplast-encoded 23S rRNA gene (Del Campo et al., 2010) and is exclusive to TR9 phycobionts.

\section{Measurements of growth and chlorophyll a fluorescence}

A $50 \mu$ l aliquot of actively growing algae resuspended in liquid Bold 3N medium $\left(1 \times 10^{6} \mathrm{cells} \mathrm{ml}^{-1}\right)$ was inoculated on cellulose-acetate disks placed on agarized medium and then cultured for 30 days at $17^{\circ} \mathrm{C}$ and $20^{\circ} \mathrm{C}$ with an irradiance of $15,30,50$ or $100 \mu \mathrm{mol} \mathrm{m}{ }^{-2} \mathrm{~s}^{-1}$ under a $14 \mathrm{~h} / 10 \mathrm{~h}$ light/dark cycle. The influence of culture conditions on algal growth was measured as biomass accumulation at the end of the culture period.

Chlorophyll a fluorescence was measured at room temperature using a pulse modulation fluorometer (PAM-2000, Walz, Effeltrich, Germany). Isolated algae grown for 3 weeks on cellulose-acetate membranes placed on semisolid culture medium were layered on filter paper that was kept moist with distilled water in order to maintain the cells in a fully hydrated state. The membranes were placed in the dark for $30 \mathrm{~min}$ after which the minimal fluorescence yield $\left(F_{\mathrm{o}}\right)$ was obtained by exciting the phycobionts with a weak measuring beam from a light-emitting diode. A saturating pulse $(800 \mathrm{~ms})$ of white light (at a photosynthetic photon fluence rate of $8000 \mu \mathrm{mol} \mathrm{m}{ }^{-2} \mathrm{~s}^{-1}$ over a wavelength band of $400-700 \mathrm{~nm}$ ), closing all reaction centres, was then applied to obtain maximal fluorescence $\left(F_{\mathrm{m}}\right)$. Variable fluorescence in darkadapted samples $\left(F_{\mathrm{v}}\right)$ was calculated as $F_{\mathrm{m}}-F_{\mathrm{o}}$. The maximum quantum yield of photosystem II (PSII) was calculated as $F_{\mathrm{v}} / F_{\mathrm{m}}$ (Schreiber et al., 1986). Subsequently, a series of 30 -s actinic light pulses $(44,65,87,139,210,315,460$, $700,1100,1700 \mu \mathrm{mol} \mathrm{m} \mathrm{m}^{-2} \mathrm{~s}^{-1}$ ) and further saturated pulses of white light were applied to determine: (i) maximum fluorescence yield during actinic illumination $\left(F_{\mathrm{m}}{ }^{\prime}\right)$; (ii) $\mathrm{Chl}$ a fluorescence yield during actinic illumination $\left(F_{\mathrm{s}}\right)$; and (iii) the level of modulated fluorescence during a brief interruption $(3 s)$ of actinic illumination in the presence of $6 \mu \mathrm{mol} \mathrm{m} \mathrm{m}^{-2} \mathrm{~s}^{-1}$ far-red light $\left(F_{0}{ }^{\prime}\right)$. The non-photochemical dissipation of absorbed light energy (NPQ) was determined at each saturating pulse according to the equation $\mathrm{NPQ}=\left(F_{\mathrm{m}}-F_{\mathrm{m}}{ }^{\prime}\right) / F_{\mathrm{m}}{ }^{\prime}$ (Bilger and Björkman, 1991). The coefficient for photochemical quenching, qp, was calculated as $\left(F_{\mathrm{m}}{ }^{\prime}-F_{\mathrm{s}}\right) /\left(F_{\mathrm{m}}{ }^{\prime}-F_{\mathrm{o}}{ }^{\prime}\right)$ (Schreiber et al., 1986). The quantum efficiency of PSII photochemistry, $\Phi_{\mathrm{PSII}}$, closely associated with the quantum yield of non-cyclic electron transport, was estimated from $\left(F_{\mathrm{m}}{ }^{\prime}-F_{\mathrm{s}}\right) / F_{\mathrm{m}}{ }^{\prime}$ (Genty et al., 1989).

\section{Acknowledgements}

This study was funded by the Spanish Ministry of Education and Science (CGL2006-12917-C02-01/02), the Spanish Ministry of Science and Innovation (CGL2009-13429-C0201/02), the AECID (PCI_A/024755/09) and the Generalitat Valenciana (PROMETEO 174/2008 GVA). We are grateful to $\mathrm{Dr}$ J. Gimeno-Romeu (University of California, Davis, USA) and to Dr P.J.G. de Nova (IREC, Ciudad Real, Spain), who were the first to isolate DNA from Ramalina farinacea thalli in our group. Wendy Ran revised the manuscript in English.

\section{References}

Angert, A.L., Huxman, T.E., Chesson, P., and Venable, D.L. (2009) Functional tradeoffs determine species coexistence via the storage effect. Proc Nat Acad Sci USA 106: 1164111645.

Baker, N.R., and Oxborough, K. (2004) Chlorophyll fluorescence as a probe of photosynthetic productivity. In Chlorophyll a Fluorescence: A Signature of Photosynthesis. Papageorgiou, G.C. (ed.). Dordrecht, The Netherlands: Springer, pp. 65-82.

Barreno, E. (2004) Hongos simbiontes: Líquenes, micoficobiosis y micorrizas. In Botánica. Izco, J. (ed.). Madrid, Spain: MacGraw-Hill Interamericana, pp. 309-340.

Barreno, E., Herrera-Campos, M., García-Breijo, F., Gasulla, F., and Reig-Armiñana, J. (2008) Non photosynthetic bacteria associated to cortical structures on Ramalina and Usnea thalli from Mexico. [WWW document]. URL http://192.104.39.110/archive/IAL6abstracts.pdf. Asilomar, Pacific Grove, CA, USA: Abstracts IAL 6- ABLS Joint Meeting, pp 5.

Beck, A., Friedl, T., and Rambold, G. (1998) Selectivity of photobiont choice in a defined lichen community: inferences from cultural and molecular studies. New Phytol 139: 709-720.

Bilger, W., and Björkman, O. (1991) Temperature dependence of violaxanthin deepoxidation and nonphotochemical fluorescence quenching in intact leaves of Gossypium hirsutum L. and Malva parviflora L. Planta 184: 226-234.

Björkman, O., and Demmig, B. (1987) Photon yield of O2 evolution and chlorophyll fluorescence characteristics at 77 $\mathrm{K}$ among vascular plants of diverse origins. Planta 170: 489-504.

Bold, H.C., and Parker, B.C. (1962) Some supplementary attributes in the classification of Chlorococcum species. Arch Mikrobiol 42: 267-288.

Catalá, M., Gasulla, F., Pradas del Real, A., García-Breijo, F., Reig-Armiñana, J., and Barreno, E. (2010) Nitric oxide is involved in oxidative stress during rehydration of Ramalina farinacea (L.) Ach. in the presence of the oxidative air pollutant cumene hydroperoxide. In Bibliotheca Lichenologica 105. Nash, T. (ed.). Stuttgart, Germany: E. Schweizerbart Science Publishers, pp. 87-92.

Cenis, J.L. (1992) Rapid extraction of fungal DNA for PCR amplification. Nucleic Acids Res 20: 2380.

Del Campo, E.M., Casano, L.M., Gasulla, F., and Barreno, E. (2009) $23 \mathrm{~S}$ rRNAs of lichen-forming trebouxia have multiple group I introns closely related to bacteria and fungi. Int Microbiol 12: 59-67.

Del Campo, E.M., Casano, L.M., Gasulla, F., and Barreno, E. (2010) Suitability of chloroplast LSU rDNA and its diverse group I introns for species recognition and phylogenetic analyses of lichen-forming Trebouxia algae. Mol Phylogenet Evol 54: 437-444.

Demmig-Adams, B., and Adams, W.W. III (1996) The role of xanthophyll cycle carotenoids in the protection of photosynthesis. Trends Plant Sci 1: 21-26.

Demmig-Adams, B., Máguas, C., Adams, W.W. III, Meyer, A., Kilian, E., and Lange, O.L. (1990) Effect of high light on the efficiency of photochemical energy conversion in a variety 
of lichen species with green and blue-green phycobionts. Planta 180: 400-409.

DePriest, P.T. (2004) Early molecular investigations of lichenforming symbionts: 1986-2001. Annu Rev Microbiol 58: 273-301.

Doering, M., and Piercey-Normore, M.D. (2009) Genetically divergent algae shape in epiphytic lichen community on jack pine in Manitoba. Lichenologist 41: 69-80.

Euzet, L., and Combes, C. (1980) Les problemes de l'especes chez les animaux parasites. In Les problemes de l'especes dans le regne animal. Bocquet, C., Génermont, J., and Lamotte, M. (eds). Paris, France: Societé Zoologique de France, pp. 239-285.

Friedl, T.H. (1989) Comparative ultrastructure of pyrenoids in Trebouxia (Microthamniales, Chlorophyta). Plant Syst Evol 164: 145-159.

Gasulla, F., de Nova, P.G., Esteban-Carrasco, A., Zapata, J.M., Barreno, E., and Guera, A. (2009) Dehydration rate and time of desiccation affect recovery of the lichen alga [corrected] Trebouxia erici: Alternative and classical protective mechanisms. Planta 231: 195-208.

Gasulla, F., Guéra, A., and Barreno, E. (2010) A simple micromethod for isolating lichen photobionts. Symbiosis 51: 175-179.

Gause, G.F. (1934) The Struggle For Existence. Baltimore, USA: Williams \& Wilkins Co.

Genty, B., Briantais, J.M., and Baker, N.R. (1989) The relationship between the quantum yield of photosynthetic electron transport and quenching of chlorophyll fluorescence. Biochim Biophys Acta 990: 87-92.

Gross, K. (2008) Positive interactions among competitors can produce species-rich communities. Ecol Lett 11: 929936.

Grube, M., Cardinale, M., Vieira de Castro, J., Müller, H., and Berg, G. (2009) Species-specific structural and functional diversity of bacterial communities in lichen symbiosis. Int Soc Microb Ecol J 3: 1105-1115.

Guzow-Krzeminska, B. (2006) Photobiont flexibility in the lichen Protoparmeliopsis muralis as revealed by ITS rDNA analyses. Lichenologist 38: 469-476.

Haruta, S., Kato, S., Yamamoto, K., and Igarashi, Y. (2009) Intertwined interspecies relationships: approaches to untangle the microbial network. Environ Microbiol 11: 2963-2969.

Honegger, R. (1991) Fungal evolution: symbiosis and morphogenesis. In Symbiosis as a Source of Evolutionary Innovation. Margulis, L., and Fester, R. (eds). Cambridge, MA, USA: The MIT Press, pp. 319-340.

Johansen, S., and Haugen, P. (2001) A new nomenclature of group I introns in ribosomal DNA. RNA 7: 935-936.

Jones, A.M., Berkelmans, R., van Oppen, M.J., Mieog, J.C., and Sinclair, W. (2008) A community change in the algal endosymbionts of a scleractinian coral following a natural bleaching event: field evidence of acclimatization. Proc Biol Sci 275: 1359-1365.

Kopecky, J., Azarkovich, M., Pfundel, E.E., Shuvalov, V.A., and Heber, U. (2005) Thermal dissipation of light energy is regulated differently and by different mechanisms in lichens and higher plants. Plant Biol 7: 156-167.

Kosugi, M., Arita, M., Shizuma, R., Moriyama, Y., Kashino, Y., Koike, H., and Satoh, K. (2009) Responses to desiccation stress in lichens are different from those in their symbionts. Plant Cell Physiol 50: 879-888.

Kranner, I., Cram, W.J., Zorn, M., Wornik, S., Yoshimura, I., Stabentheiner, E., and Pfeifhofer, H.W. (2005) Antioxidants and photoprotection in a lichen as compared with its isolated symbiotic partners. Proc Nat Acad Sci USA 102: 3141-3146.

Kroken, S., and Taylor, J.W. (2000) Phylogenetic species, reproductive mode, and specificity of the green alga Trebouxia forming lichens with the fungal genus Letharia. Bryologist 103: 645-660.

Little, A.F., van Oppen, M.J., and Willis, B.L. (2004) Flexibility in algal endosymbioses shapes growth in reef corals. Science 304: 1492-1494.

Loarie, S.R., Duffy, P.B., Hamilton, H., Asner, G.P., Field, C.B., and Ackerly, D.D. (2009) The velocity of climate change. Nature 462: 1052-1055.

Muggia, L., Grube, M., and Tretiach, M. (2008) Genetic diversity and photobiont associations in selected taxa of the Tephromela atra group (Lecanorales, lichenised Ascomycota). Mycol Prog 7: 147-160.

Nelsen, M.P., and Gargas, A. (2008) Dissociation and horizontal transmission of codispersing lichen symbionts in the genus Lepraria (Lecanorales: Stereocaulaceae). New Phytol 177: 264-275.

Niyogi, K.K., Li, X.P., Rosenberg, V., and Jung, H.S. (2005) Is PsbS the site of non-photochemical quenching in photosynthesis? J Exp Bot 56: 375-382.

O'Brien, H., Miadlikowska, J., and Lutzoni, F. (2005) Assessing host specialization in symbiotic cyanobacteria associated with four closely related species of the lichen fungus Peltigera. Eur J Phycol 40: 363-378.

Ohmura, Y., Kawachi, M., Kasai, F., and Watanabe, M. (2006) Genetic combinations of symbionts in a vegetatively reproducing lichen, Parmotrema tinctorum, based on ITS rDNA sequences. Bryologist 109: 43-59.

Piercey-Normore, M.D. (2006) The lichen-forming ascomycete Evernia mesomorpha associates with multiple genotypes of Trebouxia jamesii. New Phytol 169: 331-344.

Pombert, J.F., Lemieux, C., and Turmel, M. (2006) The complete chloroplast DNA sequence of the green alga Oltmannsiellopsis viridis reveals a distinctive quadripartite architecture in the chloroplast genome of early diverging Ulvophytes. BMC Biol 4: 3.

Rambold, G., Friedl, T., and Beck, A. (1998) Photobionts in lichens: Possible indicatorsof phylogenetic relationships? Bryologist 101: 392-397.

Romeike, J., Friedl, T., Helms, G., and Ott, S. (2002) Genetic diversity of algal and fungal partners in four species of Umbilicaria (lichenized ascomycetes) along a transect of the antarctic peninsula. Mol Biol Evol 19: 1209-1217.

Rosenberg, E., Sharon, G., and Zilber-Rosenberg, I. (2009) The hologenome theory of evolution contains Lamarckian aspects within a Darwinian framework. Environ Microbiol 11: 2959-2962.

Schreiber, U., Schliwa, U., and Bilger, W. (1986) Continuous recording of photochemical and nonphotochemical chlorophyll fluorescence quenching with a new type of modulation fluorometer. Photosynth Res 10: 51-62.

Skaloud, P., and Peksa, O. (2010) Evolutionary inferences based on ITS rDNA and actin sequences reveal extensive 


\section{M. Casano et al.}

diversity of the common lichen alga Asterochloris (Trebouxiophyceae, Chlorophyta). Mol Phylogenet Evol 54: 36-46.

Wegley, L., Edwards, R., Rodriguez-Brito, B., Liu, H., and Rohwer, F. (2007) Metagenomic analysis of the microbial community associated with the coral Porites astreoides. Environ Microbiol 9: 2707-2719.

Weis, E., and Berry, J.A. (1987) Quantum efficiency of photosystem II in relation to 'energy'-dependent quenching of chlorophyll fluorescence. Biochim Biophys Acta 894: 198208.

Wornik, S., and Grube, M. (2009) Joint dispersal does not imply maintainance of partnerships in lichen symbioses. Microb Ecol 59: 150-157.

Yahr, R., Vilgalys, R., and Depriest, P.T. (2004) Strong fungal specificity and selectivity for algal symbionts in Florida scrub Cladonia lichens. Mol Ecol 13: 3367-3378.

Yahr, R., Vilgalys, R., and DePriest, P.T. (2006) Geographic variation in algal partners of Cladonia subtenuis (Cladoniaceae) highlights the dynamic nature of a lichen symbiosis. New Phytol 171: 847-860.
Zoller, S., and Lutzoni, F. (2003) Slow algae, fast fungi: Exceptionally high nucleotide substitution rate differences between lichenized fungi Omphalina and their symbiotic green algae Coccomyxa. Mol Phylogenet Evol 29: 629640.

\section{Supporting information}

Additional Supporting Information may be found in the online version of this article:

Table S1. Location for collections of Ramalina farinacea samples used in this study.

Please note: Wiley-Blackwell are not responsible for the content or functionality of any supporting materials supplied by the authors. Any queries (other than missing material) should be directed to the corresponding author for the article. 